\title{
Prevalence of depression amongst adolescents in rural area of South India - a school based cross sectional study
}

\author{
Chakraborty T. ${ }^{1 *}$, Brahmbhatt K. ${ }^{2}$, Madappady S. ${ }^{3}$, Nelliyanil M. ${ }^{4}, \mathrm{~S} \mathrm{J.}{ }^{5}$, Debnath S. ${ }^{6}$, Anil M. ${ }^{7}$, \\ Kurulkar P V. ${ }^{8}$
}

DOI: https://doi.org/10.17511/ijphr.2016.i2.04

\begin{abstract}
1* Tamal Chakraborty, Post-graduate student, ${ }^{2}$ Krutarth Brahmbhatt, Associate Professor, Department of Community Medicine, GMERS Medical College, Junagadh, Gujarat, India. ${ }^{3}$ Sajjan Madappady, Post-Graduate Student, ${ }^{4}$ Maria Nelliyanil, Assistant Professor, ${ }^{5}$ Jayram S, Professor \& Head, ${ }^{6}$ Shubhaleena Debnath, Medical Officer, Tripura health service, Tripura, India. ${ }^{7}$ Manjula Anil, Assistant Professor, ${ }^{8}$ Kurulkar P V, Professor; 1, 3, 4, 5, 7, 8 authors affiliated with Department of Community Medicine, A.J. Institute of Medical Sciences \& Research Center, Mangaluru, Karnataka, India.
\end{abstract}

Introduction: Depression is common in adolescents and especially in high school students and is one of the most frequent mental disorders among teenagers. Depression in adolescents is an under recognized mental health problem because they remain indecisive to disclose their feelings and seldom seek psychiatric help. One of the factors that make depression so difficult to diagnose in adolescents is the common behavioural changes that are normally associated with the hormonal changes of this period. It has only been in recent years that the medical community has acknowledged childhood depression and viewed it as a condition which requires intervention. Materials and Methods: A school based cross-sectional study among adolescents was conducted by using self-administered structured "Patient Health Questionnaire-9 modified for Adolescents (PHQ-A) questionnaire" in rural field practice area of A.J. Institute of Medical Sciences \& Research Center, Mangaluru. Results: Total 284 students participated in the study and prevalence of depression was 49\%. Prevalence of depression increased with age ( $p$-value:0.001) and was higher among females ( $p$-value:0.02). Discussion: Prevalence of depression in this study matched with other studies conducted in India. Majority of the students suffered from mild depression which indicates early diagnosis is crucial in prevention of progression to moderate and severe forms of depression. Conclusion: Prevalence of depression among adolescents is high. There is an urgent need for incorporation of simple screening methods for depression in school health program.

Keywords: Adolescents, Depression, PHQ -A

\section{Corresponding Author}

Tamal Chakraborty, Post-graduate student, Department of Community Medicine, A.J. Institute of Medical Sciences \& Research Center, Mangaluru, Karnataka, India.

Email: tamalchakraborty598@gmail.com 2016-03-25

Conflict of Interest No
Review Round 1 2016-04-05

Funding

Nil

\section{How to Cite this Article}

Chakraborty T, Brahmbhatt K, Madappady S, Nelliyanil M, Jayram S, Debnath S, Anil M, Kurulkar P V. Prevalence of depression amongst adolescents in rural area of South India - a school based cross sectional study. Public Health Rev Int J Public Health Res. 2016;3(2):65-69.

Available From

https://publichealth.medresearch.in/index.php/ijphr/ article/view/33
To Browse

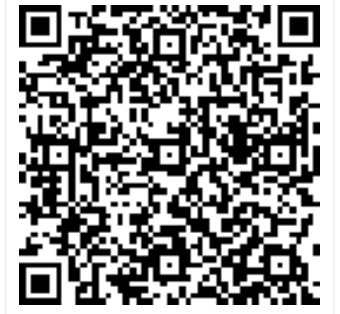

() 2016 by Tamal Chakraborty, Krutarth Brahmbhatt, Sajjan Madappady, Maria Nelliyanil, Jayram S, Shubhaleena Debnath, Manjula Anil, Kurulkar P V and Published by Siddharth Health Research and Social Welfare Society. This is an Open Access
article licensed under a Creative Commons Attribution 4.0 International License https://creativecommons.org/licenses/by/4.0/ article licensed under a Creative Commons Attribution 4.0 International License https://creativecommons.org/licenses/by/4.0/
unported [CC BY 4.0].

Review Round 3

Plagiarism X-checker $9 \%$
Review Round 2 


\section{Introduction}

Depression is a mental health condition that may begin during childhood or adolescence. Although occasional feelings of sadness and other symptoms of depression are normal for children and adolescents to experience, children and adolescents with major depressive disorder (MDD) experience one or more major depressive episodes, characterized by heightened periods of low mood and loss of interest or pleasure in their everyday life and with greater intensity for an extended period of time (at least 2 weeks).

MDD diagnosis requires five of nine specific symptoms nearly every day (depressed mood, loss of interest or pleasure in most activities, significant appetite or weight changes, changes in sleep, changes in activity, fatigue or loss of energy, guilt/worthlessness, concentration difficulties, and suicidality) that combined cause significant functional impairment across social, occupational, or educational domains [1].

While improved paediatric diagnosis alone is unlikely to significantly change patient outcomes, recognizing teenagers with depression is the first step to improved depression management. It affects $2 \%$ of pre-pubertal children and $5-8 \%$ of adolescents. The clinical spectrum of the disease can range from simple sadness to a major depressive or bipolar disorder. Studies have found that $3-9 \%$ of teenagers meet criteria for depression at any one time, and at the end of adolescence, as many as $20 \%$ of teenagers report a lifetime prevalence of depression [2].

Adolescent depression may affect the teen's socialization, family relations, and performance at school, often with potentially serious long-term consequences. Adolescents with depression are at risk for increased hospitalizations, recurrent depressions, psychosocial impairment, alcohol abuse, and antisocial behaviours as they grow up. Of course, the most devastating outcome of concern for adolescent depression is suicide, the third leading cause of death among older adolescents [3].

No perfect depression screening/assessment tool exists, but a number of adolescent depression assessment instruments do possess adequate psychometric properties to commend their use in depression detection and assessment. Optimal diagnostic procedures should combine the use by follow-up clinical interviews in which one obtains
Information from other informants (e.g., parents) and reconciles discrepant information to arrive at an accurate diagnosis and impairment assessment before treatment [4].

Depression is common in adolescents and especially in high school students and is one of the most frequent mental disorders among teenagers[5]. Depression in adolescents is an under recognized mental health problem because they remain indecisive to disclose their feelings and seldom seek psychiatric help. Care givers and teachers may not easily recognize the depressive symptoms.

Social factors do play a role in the development of depression, even though there is a biological tendency. Studying the prevalence of depression in adolescents and associated socio-demographic factors will contribute in planning the preventive and control strategies.

Childhood depression, like the depression of adults, can encompass a spectrum of symptoms ranging from normal responses of sadness and disappointment in stressful life events to severe impairment caused by clinical depression that may or may not include evidence of mania[6]. Depression is a disorder that is defined by certain emotional, behavioural and thought patterns[7].

Depressed mood is sadness at various times in response to an unhappy situation Depressive syndrome is experiencing anxiety with other symptoms such as feeling sad, lonely, unloved and worthless. Depression is under recognized among adolescents because depressive symptoms are considered a familiar part of adolescent experience[8]. Hence a study was planned in rural field practice area of a private medical college with the objective to estimate prevalence of depression among adolescent students and to study factors associated with depression.

\section{Materials and Methods}

A school based cross-sectional study was conducted in rural field practice area of A.J.Instituteof Medical Sciences \& Research Center, Mangalore. Using prevalence $65 \% 5$ with $10 \%$ error sample size was calculated to be 216 . The study was conducted from June to September 2015. One English medium school was randomly selected from 3 schools in the rural field practice area for the study. Written permission to conduct the study was obtained from the principal of the selected school. 
All the adolescent students (10-19 years) form selected school were invited to participate in the study. Participants were briefed regarding the purpose of the study and informed consent was taken from all the participants.

Data was collected using pretested structured selfadministered questionnaire which had two parts. First part contained socio-demographic information of the participants and second part assessed mental health status by "Patient Health Questionnaire-9 modified for Adolescents (PHQ-A) questionnaire" [5]. PHQ-A (Mood) has nine questions and responses to be rated on four points - not at all (score -0 ), several days (score -1 ), more than half the days (score -2 ) and nearly every day (score -3 ).

The total score was interpreted as 0-4, 5-9, 10-14, $15-20,20-27$ as none, mild, moderate, moderately severe and severe depression. Student who had severe depression and answered "yes" to any suicidal question were referred to psychiatrist for further management and follow up. Data was entered and analysed using SPSS Inc 16.0 software. Descriptive statistics were calculated and chi-square was used as test of significance. P-value $<0.05$ was considered significant.

A PHQ-9 score $\geq 11$ had a sensitivity of $89.5 \%$ and specificity of $77.5 \%$ for detecting youth meeting DSM-IV criteria for major depression on the DISCIV. On ROC analysis the PHQ-9 had an area under the curve of 0.88 ( $95 \% \mathrm{CI}=0.82$ to 0.94 ) and the cut point of 11 was optimal for maximizing sensitivity without loss of specificity.

Increasing PHQ-9 scores were significantly correlated with increasing levels of functional impairment, as well as parental report of internalizing symptoms and psychosocial problems. The sensitivity and specificity of the PHQ-9 are similar to those of adult populations. The brief nature and ease of scoring of this instrument make this tool an excellent choice for providers and researchers seeking to implement depression screening in primary care setting.

\section{Results}

Total 284 students participated in the study. Majority of the participants (95\%) belonged to age group of 12-15 years. Mean age of the participants was 14 (SD: \pm 0.9 ). Two third of the participants were Hindus (Table-1). There was near equal distribution of males $(51.8 \%)$ and female $(48.2 \%)$.

The study revealed $94(33 \%)$ of the adolescents felt depressed, irritable or hopeless on several days. In the study $85(29.9 \%)$ of the adolescents had trouble falling asleep, staying asleep, or sleeping too much for several days.

In our study $28(9.9 \%)$ of the adolescents had trouble concentrating on things like school work, reading, or watching TV nearly every day. Thirty three $(11.6 \%)$ adolescent had thoughts that they would be better off dead, or thought of hurting themselves in some way for several days. Overall summary of responses of to PHQ (Mood) questionnaire by all the participants is presented in (Table -2).

After scoring the responses, one third of the participants belonged to the category of mild depression. Almost half of the participants were normal (Table-3). Study showed significant association between age and depression. Prevalence of depression was higher in females which was statistically significant (Table-4).

Table 1: Socio-demographic profile of study participants $(n=284)$

\begin{tabular}{|l|l|l|}
\hline \multicolumn{2}{|c|}{ Variables } & \multicolumn{1}{c|}{ Frequency (\%) } \\
\hline \multirow{4}{*}{ Age } & $12-13$ & $105(37.0)$ \\
\cline { 2 - 3 } & $14-15$ & $164(57.7)$ \\
\cline { 2 - 3 } & $16-17$ & $15(5.3)$ \\
\hline \multirow{3}{*}{ Gender } & Male & $147(51.8)$ \\
\cline { 2 - 3 } & Female & $137(48.2)$ \\
\hline \multirow{3}{*}{ Religion } & Hindu & $193(68.0)$ \\
\cline { 2 - 3 } & Muslim & $86(30.3)$ \\
\cline { 2 - 3 } & Christian & $5(1.8)$ \\
\hline
\end{tabular}

Table 2: Responses to PHQ (Mood) questionnaire $(n=284)$

\begin{tabular}{|l|l|l|l|l|l|}
\hline $\begin{array}{r}\text { Sr. } \\
\text { No }\end{array}$ & \multicolumn{1}{|c|}{ Questions } & $\begin{array}{c}\text { Not at all. No. } \\
(\%)\end{array}$ & $\begin{array}{c}\text { Several days. No. } \\
(\%)\end{array}$ & $\begin{array}{l}\text { More than half the days. No. } \\
(\%)\end{array}$ & $\begin{array}{l}\text { Nearly every day. No. } \\
(\%)\end{array}$ \\
\hline 1. & Feeling down, depressed, irritable or hopeless? & $161(56.7)$ & $94(33.1)$ & $25(8.8)$ & $4(1.4)$ \\
\hline 2. & Little interest or pleasure in doing things? & $136(47.9)$ & $104(36.6)$ & $29(10.2)$ & $15(5.3)$ \\
\hline 3. & $\begin{array}{l}\text { Trouble falling asleep, staying asleep, or sleeping too } \\
\text { much? }\end{array}$ & $154(54.2)$ & $85(29.9)$ & $32(11.3)$ & $13(4.6)$ \\
\hline
\end{tabular}




\begin{tabular}{|c|c|c|c|c|c|}
\hline 4. & Poor appetite, weight loss or overeating? & $150(52.8)$ & $96(33.8)$ & $31(10.9)$ & $7(2.5)$ \\
\hline 5. & Feeling tired or having little energy? & $133(46.8)$ & $111(39.1)$ & $29(10.2)$ & $11(3.9)$ \\
\hline 6. & Feeling bad about yourself- & $190(66.9)$ & $69(24.3)$ & $15(5.3)$ & $10(3.5)$ \\
\hline 7. & Trouble concentrating on things like school work, reading, or watching TV? & $118(41.5)$ & $106(37.3)$ & $32(11.3)$ & $28(9.9)$ \\
\hline 8. & Moving or speaking so slow that other people could have noticed? & $186(65.5)$ & $62(21.8)$ & $20(7.0)$ & $16(5.6)$ \\
\hline 9. & Thoughts that you would be better off dead, or of hurting yourself in some way & $234(82.4)$ & $33(11.6)$ & $12(4.2)$ & $5(1.8)$ \\
\hline
\end{tabular}

Table3: Distribution of study population as per severity of depression $(n=139)$

\begin{tabular}{|l|l|l|}
\hline \multicolumn{1}{|c|}{ Variables } & Frequency & Percentage \\
\hline $5-9$ (Mild) & 94 & 67.6 \\
\hline $10-14$ (Moderate) & 32 & 23.0 \\
\hline $15-20$ (Moderately severe) & 12 & 8.6 \\
\hline $20-27$ (Severe) & 1 & 0.8 \\
\hline Total & 139 & $100 \%$ \\
\hline
\end{tabular}

Table4: Association of depression with age and gender $(n=284)$

\begin{tabular}{|l|l|l|l|l|}
\hline \multicolumn{2}{|c|}{ Variables } & \multicolumn{2}{c|}{ Depression } & \multirow{2}{*}{ P-value } \\
\cline { 3 - 4 } \multicolumn{2}{|c|}{} & No (\%) & Yes (\%) & \\
\hline \multirow{3}{*}{ Age } & $12-13$ & $70(66.7 \%)$ & $35(33.3 \%)$ & \multirow{2}{*}{0.001} \\
\cline { 2 - 4 } & $14-15$ & $73(44.6)$ & $91(55.4 \%)$ & \\
\cline { 2 - 4 } & $16-17$ & $2(13.4)$ & $13(86.6 \%)$ & \\
\hline \multirow{2}{*}{ Gender } & Male & $62(42.1)$ & $85(57.9)$ & 0.02 \\
\cline { 2 - 4 } & Female & $54(39.5)$ & $83(60.5)$ & \\
\hline
\end{tabular}

\section{Discussion}

Overall prevalence of depression among adolescents in this study was $49 \%$. Prevalence of depression in our study is higher than a study conducted in Noida, Uttar Pradesh (38\%) [10]. However, a study conducted in Bellary, Karnataka reported prevalence of depression amongst adolescent's students as $65 \%$ [11]. A study conducted amongst adolescents in Raipur, India reported prevalence of depression as $59 \%$ [12].

A study conducted in Chennai also reported prevalence of depression amongst adolescents up to $60 \%$ [13]. Out of the total number of students found positive for depression, two third were suffering from mild depression. This shows that adolescents are vulnerable to depression and early detection through opportunistic screening can prevent progression to moderate and severe forms of depression.

Prevalence of depression was found higher among females $(60.5 \%)$ than males $(58 \%)$. This finding has been substantiated by other studies $[11,12,13,14]$. Psychosocial variables like selfesteem, mastery and coping have been found to be
Stronger in boys than girls therefore explaining their better ability to cope with depression. However, these psychosocial variables needs to be further evaluated.

The present study showed that older adolescents were experiencing more depressive symptoms than younger adolescents this finding was substantiated by a study conducted in Chennai [13].Adolescents may be experiencing more stress coping with the transition and also other stressors like peer influence, autonomy, independence from family and difficulties in social adjustment.

This finding needs to be confirmed by further studies. This means that providing health education regarding depression to adolescents at early age is very crucial to prevent increase in prevalence of depression during mid-adolescence and late adolescence stages.

\section{Conclusion}

Prevalence of depression amongst adolescents is high. As majority of the depressed students belonged to mild category screening has got important role in prevention of progression to moderate and severe categories. Prevalence of depression increases with age and is higher among females.

\section{Limitations}

As the questionnaire was self-administered; information bias can't be ruled out. As this was a cross-sectional study temporality of the associations found in the study needs to be further assessed by longitudinal studies. Though the questionnaire used (PHQ-A) is validated and has got good sensitivity and specificity; its not a gold standard. Questionnaire gives information regarding participants' mental status of prior two weeks.

\section{Acknowledgement}

We extend our sincere thanks to all the participants, school teachers and principal of the school. 


\section{Reference}

01. Siu AL. Screening for Major Depressive Disorder Among Children and Adolescents- A Systematic Review for the US Preventive Services Task Force. AHRQ. 13-05192-EF-1; Sept 2015.

[Crossref]

02. Zuckerbrot RA, Jensen PS. Improving recognition of adolescent depression in primary care. Arch Pediatr Adolesc Med. 2006 Jul;160(7)694-704.

[Crossref]

03. Centers for Disease Control and Prevention National Center for Injury Prevention and Control. Web-based Injury Statistics Query and Reporting System (WISQARS). Available from: [Article] [Crossref]

04. Lasaa L, Ayuso-Mateos JL, Vazquez-Barqueroa JL, Diez-Manriquea EJ, Dowrickb CE. The use of the Beck Depression Inventory to screen for depression in the general population- a preliminary analysis. Journal of Affective Disorders. 2000;57(1)261-265.

[Crossref]

05. Daryanavard A, Madani A, Mahmoodi M S, Rahimi S, Nourooziyan F, Hosseinpoor M. Preval ence of Depression among High School Students and its Relation to Family Structure. American Journal of Applied Sciences. 2011;8(1)39-44.

[Crossref]

06. K Nagendra, D Sanjay, C Gouli, NK Kalappanavar, CS Vinod Kumar. Prevalence and association of depression and suicidal tendency among adolescent students. Int Journal of Bio Med and Advance Res. 2012;3(9)714-719.

[Crossref]

07. Steinberg L. Adolescence, 5th ed. New YorkMcGraw-Hill. 1998.

[Crossref]

08. Mohanraj R, Subbaiah K. Prevalence of depressive symptoms among urban adolescents in South India. J Indian Assoc Child Adolesc Ment Health. 2010;6(2)33-43.

[Crossref]

09. Richardson LP, McCauley E, Grossman DC, McCarty CA, Richards J, Russo JE, et al. Evalua tion of the Patient Health Questionnaire (PHQ-9) for Detecting Major Depression among Adole scents. Pediatrics. 2010 dec;126(6)1117-23.

[Crossref]
10. Chauhan S, Lal $\mathrm{P}, \mathrm{Naya} \mathrm{kH}$. Prevalence of Depression among School Children aged 15 years and above in a Public School in Noida, Uttar Pradesh. Journal of Academia and Industrial Research (JAIR). 2014;3(6)269-273. [Crossref]

11. Goud TG, Ramesh K, Kumar KP. Factors Associated With Depression among Adolescents. RRJMHS. 2014;3(4)73-76.

[Crossref]

12. Verma $N$, Jain $M$, Roy P. Assessment of Magnitude and Grades of Depression among Adolescents in Raipur City, India. Int Res J Medi Sci. 2014;2(5)10-13.

[Crossref]

13. Mohanraj R, Subbaiah K. Prevalence of depressive symptoms among urban adolescents in South India. J Indian Assoc Child Adolesc Ment Health. 2010;6(2)33-43.

[Crossref]

14. Compas BE, Oppendisano G, Connor JK. Gender difference in depressive symptoms in adolescents- Comparison of national samples of clinically and non-referred youths. Journal of consulting clinical psychology. 1997;65(4)617626.

[Crossref]

15. Kroenke K, Spitzer R, Williams W. The phq-9validity of a brief severity measures. JGIM. $2001 ; 16 ; 606-616$.

[Crossref] 